\title{
Usability of a novel disposable autoinjector device for ixekizumab: results from a qualitative study and an open-label clinical trial, including patient- reported experience
}

\author{
This article was published in the following Dove Press journal: \\ Medical Devices: Evidence and Research \\ 12 October 2016 \\ Number of times this article has been viewed
}

\author{
Kristina Callis Duffin' \\ Michael Bukhalo² \\ Margaret A Bobonich ${ }^{3}$ \\ David Shrom ${ }^{4}$ \\ Fangyi Zhao ${ }^{4}$ \\ James R Kershner ${ }^{4}$ \\ Anne Gill ${ }^{4}$ \\ Beth Pangallo 4 \\ Catherine L Shuler ${ }^{4}$ \\ Jerry Bagel ${ }^{5}$ \\ 'Department of Dermatology, \\ University of Utah School of \\ Medicine, Salt Lake City, UT, \\ ${ }^{2}$ Arlington Dermatology, Arlington \\ Heights, IL, ${ }^{3}$ CWRU Schools of \\ Medicine and Nursing, Case Western \\ Reserve University Cleveland, $\mathrm{OH}$, \\ ${ }^{4}$ Lilly Research Labs, Eli Lilly and \\ Company, Lilly Corporate Center, \\ Indianapolis, IN, ${ }^{5}$ Psoriasis Treatment \\ Center of Central New Jersey, East \\ Windsor, NJ, USA
}

Background: Most biologic therapies for psoriasis are delivered via subcutaneous injection. Ixekizumab, an anti-interleukin 17A monoclonal antibody approved for patients with moderateto-severe plaque psoriasis, is delivered subcutaneously via prefilled syringe or autoinjector. Here we report the results of an ixekizumab autoinjector usability study as well as the patient-reported experience with the autoinjector in a clinical trial.

Methods: The usability study enrolled 49 subjects (patients with a range of autoimmune conditions or their caregivers). Subjects were randomized to a trained or untrained group and were evaluated for their ability to perform an injection successfully when provided the device and the instructions for use. In the clinical trial, 102 subjects (patients with psoriasis or their caregivers) used the autoinjector to deliver injections of ixekizumab ( $80 \mathrm{mg}$ every 2 weeks after a starting dose of $160 \mathrm{mg}$ ). At weeks 0,4 , and 8 , subjects completed the subcutaneous administration assessment questionnaire, which assesses the ease of use and confidence with using an injection device.

Results: In the usability study, all subjects in the untrained arm performed successful injections, while two subjects in the trained arm had an injection failure. These incidences were not consistent with any pattern of issues with the device or the instructions for use. In the clinical trial, there were two injection failures of 674 total self-injections performed over 12 weeks. At the first use of the device, $95 \%$ of subjects either agreed or strongly agreed that the device was "overall easy to use", and they felt "confident the dose was complete" according to the subcutaneous administration assessment questionnaire.

Conclusion: The ixekizumab autoinjector was used successfully by patients and caregivers with or without training. Subjects using the autoinjector in a clinical trial felt it was easy to use and felt confident while using it.

Trial Registration: NCT01777191.

Keywords: ixekizumab, autoinjector, ease of use, usability, confidence

\section{Introduction}

Psoriasis (Ps) is a chronic, immune-mediated inflammatory skin disease, and many patients with moderate-to-severe disease require continuous long-term systemic treatment. Although biologics have demonstrated efficacy, safety, and tolerability, long-term outcomes are dependent on the patients' long-term adherence. ${ }^{1-5}$ Most biologic therapies are self-administered via subcutaneous injection. In patients with Ps, self-injection may be impacted by reduced fine motor skills due to comorbid rheumatoid arthritis

\footnotetext{
Correspondence: David Shrom

Eli Lilly and Company, Lilly Corporate Center, Indianapolis, IN, 46220, USA

Tel +l 3173546328

Email shromda@lilly.com
} 
(RA) or psoriatic arthritis (PsA), or disease involvement of the distal digits and/or nails, and these issues may promote nonadherence. In addition, forgetfulness, injection anxiety, and injection fatigue are among the most common reasons for nonadherence to therapeutic regimens. . $^{2,3,6-8}$

Autoinjector devices have been developed with a number of different features, which make self-injection easier for patients. There are currently a number of autoinjectors available to patients for administration of biologic therapies indicated for the treatment of Ps. ${ }^{9,10}$ Autoinjectors can increase tolerability and satisfaction with injections as well as adherence compared to manual injection methods. ${ }^{9-13}$

Ixekizumab, an anti-interleukin 17A monoclonal antibody, is a biologic therapy currently approved for the treatment of moderate-to-severe plaque Ps that is delivered via subcutaneous injection with an autoinjector or a prefilled syringe. Phase III clinical trials have shown that ixekizumab is highly effective in treating Ps, providing rapid, long-lasting improvements in skin clearance and quality of life with an acceptable safety profile. ${ }^{14,15}$ In addition, the pharmacokinetic profile of ixekizumab is equivalent when delivered by autoinjector or prefilled syringe. ${ }^{16}$

The single use autoinjector for the self-administration of ixekizumab was engineered to be simple to use and easy to operate while minimizing injection errors. The design principles applied to the ixekizumab autoinjector were informed by human factors research, as well as qualitative and quantitative surveys and interviews with patients, health care providers, and caregivers that sought to understand the ideal characteristics of a device while taking into account the varying degrees of patient capabilities and the ways in which patients interact with a device. Here we report the results of two separate studies: 1) a usability study with the autoinjector, which evaluated patients with a variety of autoimmune diseases for their ability to successfully perform an injection; and 2) a Phase III clinical study, UNCOVER-A, in which the overall experience of patients with Ps using the autoinjector to administer ixekizumab was evaluated.

\section{Methods}

\section{The autoinjector device}

The autoinjector for ixekizumab is a single-use device containing $80 \mathrm{mg}$ of ixekizumab (Figure 1). The design features of the autoinjector were informed by 13 separate qualitative and quantitative studies and three human factor studies (Eli Lilly and Company, data on file) (Figure 2), which included over 1,000 patients with systemic lupus erythematosus (SLE), Ps, PsA, RA, ankylosing spondylitis (AS), health care providers

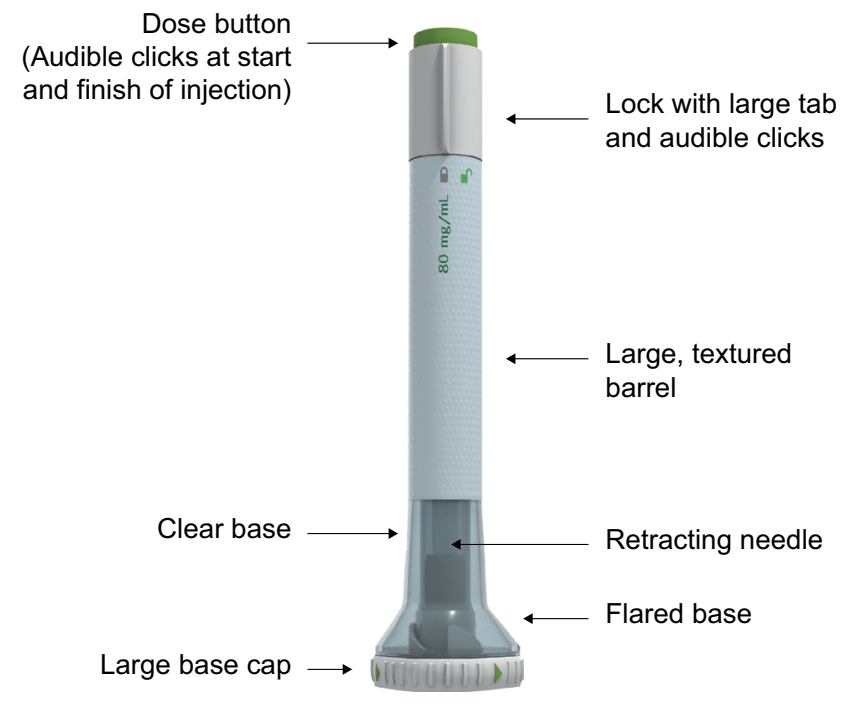

Figure I Ixekizumab autoinjector.

(rheumatologists and dermatologists), and caregivers from multiple countries (USA, Germany, Japan, France, and Italy).

Based on this qualitative and quantitative research, several design principles were identified: 1) the device should be easy to use by patients with a range of physical abilities or comorbid conditions impacting dexterity; 2) the device operation should be easy to understand; 3) patients should feel confident that they are delivering the dose successfully and using the device appropriately; and 4) the device can be safely used and disposed of. The autoinjector for ixekizumab has features consistent with these principles (Table 1 and Video S1).

To perform the injection, patients or caregivers first remove the base cap, and place the clear base flat against the skin at the injection site (Table 2). The flared base eliminates the need for pinching up the skin. Next, patients unlock the device and press the injection button. An audible click is heard indicating the start of the injection followed by a second click ( $<10$ seconds from the first audible click) confirming that the injection is complete and that the needle has retracted.

\section{Usability study design}

Prior to conducting the usability study, the protocol, informed consent, advertising, and other supporting documents were reviewed and approved by the institutional review board (Batelle Memorial Institute IRB, Columbus OH, USA). All participants provided written informed consent before enrollment.

This usability study included patients with self-reported SLE, Ps, PsA, AS, or RA and caregivers with no professional health care-related training who had responsibility for administering care to other adults or juveniles (eg, 


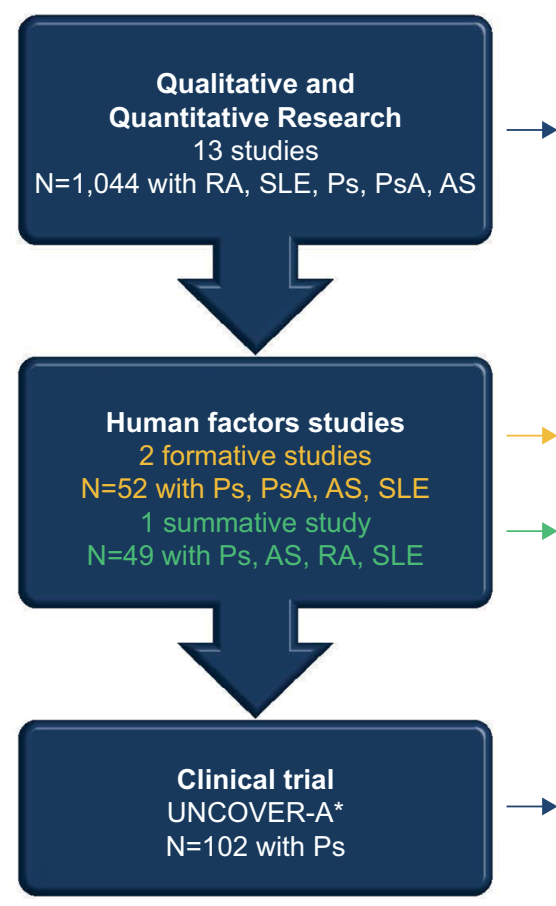

*Primary objectives reported previously
Design principles defined

- Easy to use

- Easy to understand

- Easy dose confirmation

- Safe to use

Patient experience evaluated

Ps patients report the ease of use

of the device and their confidence using the device ${ }^{* *}$

${ }^{* *}$ Results from these studies reported here

Figure 2 Summary of research informing the design and validation of the autoinjector.

Abbreviations: AS, ankylosing spondylitis; Ps, psoriasis; PsA, psoriatic arthritis; RA, rheumatoid arthritis; SLE, systemic lupus erythematosus.

Table I Summary of autoinjector features

\begin{tabular}{|c|c|}
\hline Design principle & Features \\
\hline $\begin{array}{l}\text { Easy to use } \\
\text { The device should be easy to } \\
\text { manipulate, with different ways of } \\
\text { holding or interacting with it for } \\
\text { patients with a range of physical } \\
\text { abilities }\end{array}$ & $\begin{array}{l}\text { - Large dose button } \\
\text { - Wide body diameter with } \\
\text { textured surface } \\
\text { - Large base cap } \\
\text { - Triangular base keeps device } \\
\text { stable vertically or horizontally } \\
\text { during storage }\end{array}$ \\
\hline $\begin{array}{l}\text { Easy to understand } \\
\text { The device operation should be } \\
\text { intuitive with minimal steps }\end{array}$ & $\begin{array}{l}\text { Wide flared base allows device } \\
\text { to be held stably at the point of } \\
\text { injection and eliminates the need } \\
\text { for pinching up the skin or to use } \\
\text { a specific injection angle }\end{array}$ \\
\hline $\begin{array}{l}\text { Easy dose confirmation } \\
\text { Patients should feel confident } \\
\text { that they are using the device } \\
\text { appropriately with confirmation } \\
\text { that they are successfully delivering } \\
\text { their dose }\end{array}$ & $\begin{array}{l}\text { - Clear base allows visualization of } \\
\text { the injection site and drug solution } \\
\text { - Audible clicks at the beginning } \\
\text { and end of the injection provide } \\
\text { auditory confirmation of dose } \\
\text { delivery }\end{array}$ \\
\hline $\begin{array}{l}\text { Safe to use } \\
\text { The device can be safely used and } \\
\text { disposed of }\end{array}$ & $\begin{array}{l}\text { - Easy-to-move lock prevents } \\
\text { misfiring of the device } \\
\text { - A needle that retracts after the } \\
\text { injection is complete }\end{array}$ \\
\hline
\end{tabular}

relatives, friends, or neighbors). All study subjects were aged 18 years and older. Subjects were excluded if they were physically unable to perform the protocol procedures, had a known hypersensitivity or allergy to sterile placebo or
Table 2 Tasks performed for injection

\begin{tabular}{|c|c|}
\hline Get ready & $\begin{array}{l}\text { I. Let autoinjector come to room temperature for } \\
30 \text { minutes after taking out of refrigerator } \\
\text { 2. Inspect the autoinjector to ensure: } \\
\text { a. solution does not look cloudy or discolored or } \\
\text { contain small specks } \\
\text { b. it is not damaged or past expiration date } \\
\text { 3. Choose injection site (thigh, abdomen, back of arm) }\end{array}$ \\
\hline \multirow[t]{5}{*}{ Inject } & 4. Make sure lock is in lock position \\
\hline & 5. Twist off cap \\
\hline & 6. Place clear base flat against skin \\
\hline & 7. Unlock device \\
\hline & 8. Press injection button and hold for 10 seconds \\
\hline Finish & 9. Dispose \\
\hline
\end{tabular}

were pregnant, breastfeeding, or planned to become pregnant during the course of the study (patients only). Study subjects with self-reported past medical history of bleeding disorders, human immunodeficiency virus/acquired immunodeficiency syndrome, or hepatitis B or C (per reported medical history) were also excluded from the study.

The primary objective of the usability study was to evaluate the proportions of patients who perform successful injections with or without supplemental training. Enrolled subjects were randomized into one of two study groups (trained or untrained). All subjects completed a simulated health care practitioner office visit, in which they were provided with 
basic prescription information about ixekizumab, including indication for use, dose, and dose frequency. Subjects assigned to the trained arm were further trained on the use of the device. The investigator guided subjects through the instructions for use and demonstrated the autoinjector by delivering an injection into an injection pad. The subject then performed a practice injection into an injection pad while the investigator observed, answered questions, and corrected for proper technique as needed.

After a decay period ( $\geq 1$ day and $\leq 1$ week) each subject performed an injection (patients self-injected and caregivers injected into an injection pad). The investigator provided an autoinjector prefilled with $1.0 \mathrm{~mL}$ of sterile placebo and the instructions for use of the device. The investigator then instructed the subject to follow the steps in the provided instructional material to perform an injection. Each injection was recorded as a success by the investigator if the participant administered the complete dose. All failures were investigated during an interview to understand the root cause and the extent to which the design of the device, carton, or instructions for use may have contributed to the failure.

\section{UNCOVER-A study design: assessing the patient experience}

The study design and primary results, including safety findings, for the UNCOVER-A trial were reported previously. ${ }^{16}$ Briefly, in this randomized, open-label, Phase III study, patients with moderate-to-severe Ps were assigned by a computer-generated random sequence to an injection device (prefilled syringe or autoinjector). Patients received $80 \mathrm{mg}$ ixekizumab as one subcutaneous injection every 2 weeks, following a $160 \mathrm{mg}$ initial dose at week 0 (baseline visit; administered as two $80 \mathrm{mg}$ injections). At baseline, the first injection was demonstrated and performed by the investigator or staff. All remaining injections were performed by the patient or caregiver, and a study drug administration log was completed. The log documented the date, time, and location of administration; the administrator (patient or caregiver) of ixekizumab; whether ixekizumab was fully administered, and if not, what the reason(s) were from a list provided (study drug leaked from autoinjector, study drug leaked from injection site, hard to hold, autoinjector jammed during injection, study drug administration instructions were difficult to understand, or other). Site personnel completed a product complaint form for each operation failure reported on a study drug administration $\log$.

The study received investigational review board approval for each site (Western Institutional Review Board, Puyallup,
Table 3 SQAAQ questionnaire

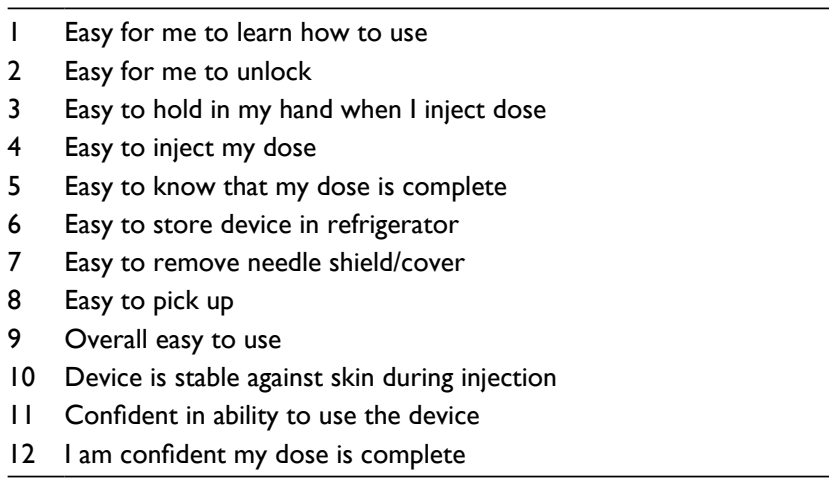
Response options:

(I) Strongly disagree; (2) Disagree; (3) Slightly disagree; (4) Neither agree nor disagree; (5) Slightly agree; (6) Agree; (7) Strongly agree

Abbreviation: SQAAQ, subcutaneous administration assessment questionnaire.

Washington, USA; University of Utah Institutional Review Board, Utah, USA), and all enrolled patients provided written informed consent.

The primary objective was to evaluate the pharmacokinetics of ixekizumab delivered via autoinjector or prefilled syringe. ${ }^{16}$ A secondary objective was to evaluate the patient/ caregiver experience with the autoinjector using the subcutaneous administration assessment questionnaire (SQAAQ). The SQAAQ is a novel, 12-item, self-administered questionnaire that assesses ease of use of the device and patient confidence while using the device to administer a subcutaneous injection of drug (Table 3 ). This instrument has not yet been psychometrically validated. At weeks 0,4 , and 8 of the study, patients and injection assistants assessed their experience with the autoinjector using the SQAAQ. Each item was answered on a 7-point Likert scale ranging from "strongly disagree" to "strongly agree". For each SQAAQ item, the number and percentage of patients who answered "strongly agree" or "agree" were summarized at weeks 0, 4, and 8 (observed case data). Here we report only results for those patients assigned to the autoinjector.

\section{Results}

\section{Baseline characteristics and disposition}

Forty-nine patients or caregivers participated in the usability study. There were 14 males and 35 females with an average age of 53.5 years. The study included eight patients with SLE, eleven with RA, eight with PsA, nine with Ps only, and seven with AS.

Baseline characteristics of Ps patients participating in UNCOVER-A were previously reported. ${ }^{16}$ Briefly, 102 patients were assigned to use the autoinjector. Among these patients, the majority were male $(70 \%)$ and Caucasian $(93.1 \%)$ with a mean age of 46.8 years. Twenty-six percent 
Table 4 Usability study: summary of injection failures in patients and caregivers by training arm

\begin{tabular}{lll}
\hline Training group & User group & $\begin{array}{l}\text { Injection } \\
\text { failures }\end{array}$ \\
\hline Trained $(n=17)$ & Patients $(n=14)$ & 2 \\
& Caregivers $(n=3)$ & 0 \\
Untrained $(n=32)$ & Patients $(n=29)$ & 0 \\
& Caregivers $(n=3)$ & 0 \\
\hline
\end{tabular}

reported comorbid PsA and $38 \%$ had nail Ps, consistent with the study population of other Phase III trials of ixekizumab. ${ }^{14}$ Ninety-two percent of patients completed the 12-week treatment period.

\section{Successful use of autoinjector: usability study}

All untrained subjects completed a successful injection, while two patients in the trained arm failed to deliver a dose (Table 4). One patient was a 73-year-old female with SLE who was injection-naïve. This patient turned the locking ring back-and-forth several times while attempting to depress the injection button when it was in a locked position and ultimately abandoned the task. She had a number of comorbidities, including chronic pain, depression, and fibromyalgia and had 17 daily prescription medications, including some affecting cognitive function. The other injection failure occurred in a 56-year-old female with AS who was injection-experienced. This patient was unable to fully depress the injection button after unlocking the autoinjector. During the interview, she indicated that she had understood how to perform the injection, and no specific issues with the instructions for use were identified.

\section{Patient-reported experience with the ixekizumab autoinjector: UNCOVER-A}

In the UNCOVER-A study, patients or caregivers performed one injection at week 0 for the starting dose and one injection every other week for 12 weeks. After the first use of the autoinjector at week $0, \geq 90 \%$ "agreed" or "strongly agreed" with each item in the SQAAQ (Figure 3). In addition, after the first use, 95\% "agreed" or "strongly agreed" that the autoinjector was "overall easy to use" and 98\% "agreed" or "strongly agreed" that they were "confident that the dose was complete". With continued experience with the autoinjector over the course of the trial, the proportions of patients or caregivers agreeing or strongly agreeing with each item of the SQAAQ continued to increase at week 4 and 8 . At week $8, \geq 95 \%$ "agreed" or "strongly agreed" with each item, and 98\% "agreed" or "strongly agreed" that the device was "overall easy to use"; 99\% "agreed" or "strongly agreed" that the device was "easy to learn how to use", "easy to unlock", "easy to pick up", and it was "easy to know the dose was complete".

\section{Device failures during UNCOVER-A}

A total of 674 injections were performed over weeks $0,2,4$, 6,8 , and 10 . Of these 674 injections, there were two single occurrences of a failure to administer a complete dose. Both instances occurred at week 10 (sixth self-injection). In one instance, the patient, a 46-year-old man, reported drug leaking from the device, and this was due to a faulty device in which the needle did not deploy. In the other instance, the patient, a 54-year-old man, reported drug leaking from the injection site and this was likely due to the injection being too shallow into the epidermis.

\section{Discussion}

The use of biologic treatments over long time periods is common in the treatment of Ps, and is generally effective and safe. Autoinjection devices may improve treatment-related challenges, including injection anxiety, injection fatigue, and functional impairment. ${ }^{3,7,8}$ Furthermore, the use of autoinjectors positively correlates with medication adherence, which is known to be lower in patients with chronic diseases. ${ }^{13}$

Qualitative and quantitative research with patients, caregivers, and health care professionals informed the design principles used for the ixekizumab autoinjector. There are many features that enable it to be used safely and easily with minimal errors or injection failures. The device has an ergonomic shape, grip, and dose button, which allow the device to be interacted with in different ways. There is a lock to prevent the device from misfiring. Its clear body allows the injection site and drug solution to be visualized so that there is confirmation that the full dose is delivered. In addition, audible clicks confirm the start and completion of the dose. Compared to other autoinjectors, it has a wider base, which eliminates the need to pinch up the skin. ${ }^{17-19}$

The results presented here demonstrate that the ixekizumab autoinjector can be used by patients or their caregivers with or without training, and the vast majority of patients and caregivers report that the autoinjector was "overall easy to use" and that they were "confident using the device". Furthermore, failures to deliver a complete dose were uncommon.

The usability study demonstrated that the majority of patients with any of the represented autoimmune conditions or caregivers successfully performed injections with or 


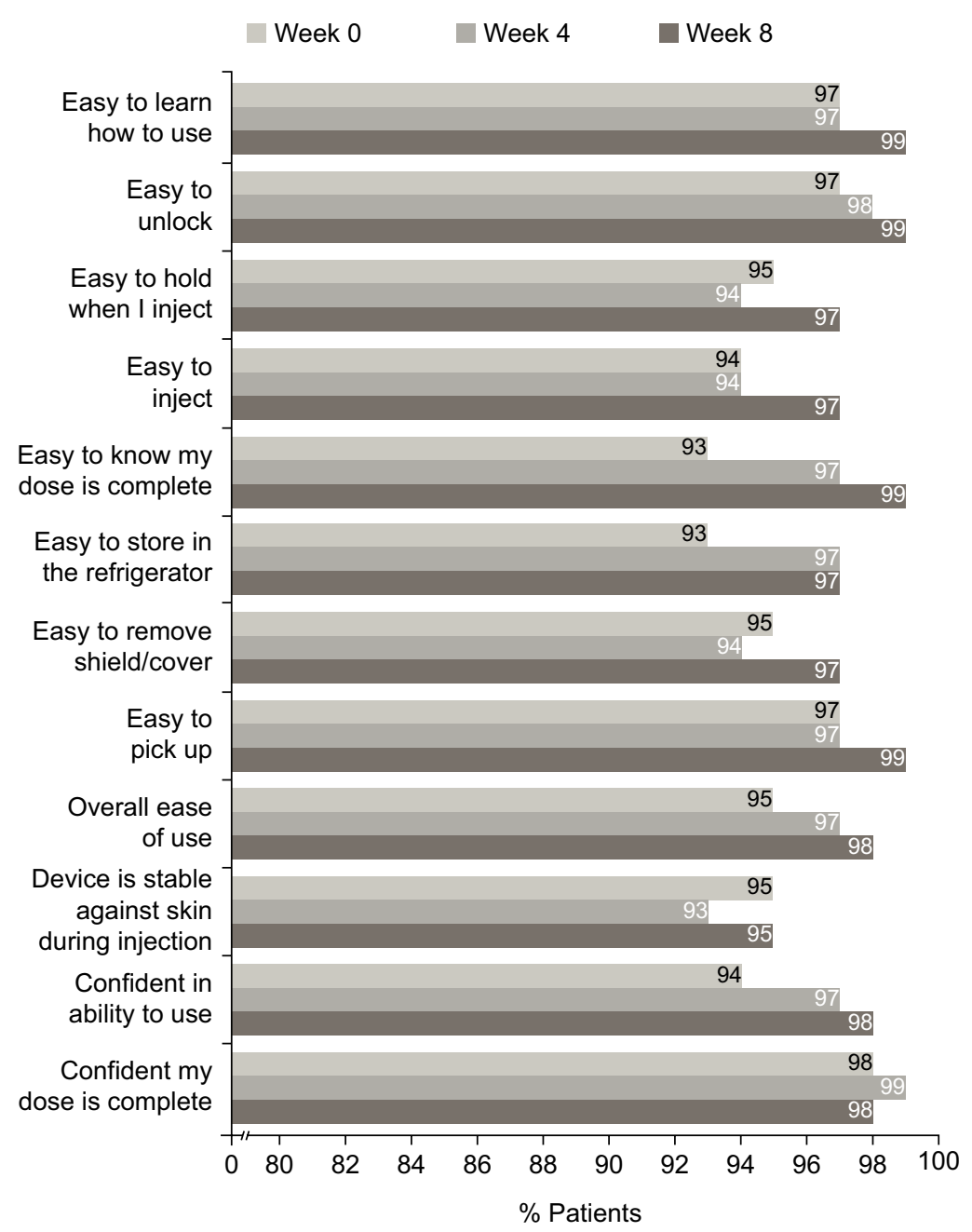

Figure 3 Patient responses to the SQAAQ weeks 0-4 and 8 (observed case data).

Notes: The proportion of patients that agreed or strongly agreed to each item of the SQAAQ is shown. Missing data were not imputed. Abbreviation: SQAAQ, subcutaneous administration assessment questionnaire.

without training. Notably, all patients and caregivers in the untrained arm performed successful injections when provided the autoinjector and the instructions for use. The two failed injections, which occurred in the trained arm, were not consistent with any pattern of issues with the device or the instructions for use. Overall, while these data indicate that patients can self-inject with or without training, for some patients, additional training or injection support may be required (eg, injection performed by caregiver). The failure rate in this usability study is in line with other human factor studies of autoinjectors for biologic therapies for autoimmune diseases. ${ }^{19-21}$

Consistent with the high rates of successful injection observed in the usability study, nearly all patients selfadministered all of their doses successfully in UNCOVER-A. All patients performed injections successfully at week 0 (first use) and week 2, when errors would be most expected. There were two failed injections out of 674 total injections during the study $(0.3 \%)$, which corresponds to one failed injection for one patient every 20 years according to ixekizumab's approved dosing regimen (17 injections per year). The two failed injections occurred at week 10 after each patient had already performed six successful injections. These data are consistent with usability testing in clinical trials of other autoinjectors that are currently available in Ps and RA. ${ }^{10,19}$

The vast majority of patients with Ps or caregivers "agreed" or "strongly agreed" with each item of the SQAAQ at weeks 0 , 4 , and 8 . Notably, at week $0,95 \%$ considered it to be "overall easy to use" and $98 \%$ were "confident their dose was complete". Patient/caregiver assessment of the autoinjector was consistent over time with the numbers of patients/caregivers agreeing or strongly agreeing with each item being similar or slightly increased between weeks 0 and 4 and between weeks 4 and 8 . While formal comparisons were not conducted, 
numerically more patients/caregivers agreed or strongly agreed with each question on the SQAAQ relative to the prefilled syringe used in this trial at each time point (Figure S1).

The SQAAQ is a novel instrument designed to assess confidence with using and ease of use of an injection device that has not yet been validated. There is no standard questionnaire or instrument that is employed to evaluate usability and patient preference for an injection device, and several different instruments have been used to evaluate the patient experience with autoinjectors in Ps and other disease states. ${ }^{9,10,20-23}$ Overall, the patient-/caregiver-reported data on the experience with the device presented in this report is consistent with other studies of autoinjector devices in $\mathrm{Ps}^{9,10}$ that also have high acceptance and convenience.

\section{Conclusion}

Patients with Ps and other autoimmune diseases often receive treatments that need to be self-administered in the form of a subcutaneous injection. As the complexity of a treatment regimen is associated with low patient adherence, ${ }^{5}$ autoinjector devices, which simplify injections, are intended to foster greater adherence to biologic regimens. ${ }^{13}$ Results from this study support the ease of use of this autoinjector as a method for subcutaneous delivery of ixekizumab in subjects with moderate-to-severe plaque Ps, and the use of the autoinjector may facilitate treatment satisfaction and adherence to longterm therapy. Further research is required to test the longterm impact on adherence to treatment with this autoinjector.

\section{Acknowledgments}

The authors would like to thank the UNCOVER-A investigators, investigators involved in the usability study as well as the patients who participated. These studies were funded by Eli Lilly and Company. Employees of the sponsor participated in study design and data collection, analysis, and interpretation of the data.

\section{Author contributions}

$\mathrm{KCD}, \mathrm{MB}$, and JB participated in acquisition of data and interpretation of data. AG, CLS, JRK, BP, and FZ participated in study design, acquisition of data, and interpretation of data. DS and MAB participated in interpretation of data. The first draft of the manuscript was written by DS and critically revised by all authors. All authors agreed to submit the final version. All authors critically revised the paper and approved its final version, and take responsibility for its content. All authors contributed toward data analysis, drafting and critically revising the paper and agree to be accountable for all aspects of the work.

\section{Disclosure}

$\mathrm{KCD}$ is an investigator for and received research grants from Amgen, Eli Lilly, Janssen, Stiefel, Abbvie, BMS, Celgene, Pfizer, Novartis, Xenoport and served as a consultant for Amgen, Eli Lilly, Janssen, Steifel, Abbvie, BMS, Celgene, Pfizer, Novartis, and Xenoport; JB has been a speaker and received honoraria from Janssen, Abbvie, Novartis, Celgene, Leo and was an investigator for and received research grants from Janssen, Abbvie, Novartis, Celgene, Leo, Boehringer Ingelheim, and Eli Lilly and was a consultant for and received honoraria for Eli Lilly. MAB and MB have no disclosures; DS, AG, CLS, BP, JRK, and FZ are employees at and stockholders of Eli Lilly. The authors report no other conflicts of interest in this work.

\section{References}

1. Serup J, Lindblad AK, Maroti M, Kjellgren KI, Niklasson E, Ring L, Ahlner J. To follow or not to follow dermatological treatment--a review of the literature. Acta Derm Venereol. 2006;86(3):193-197.

2. Bewley A, Burrage DM, Ersser SJ, Hansen M, Ward C. Identifying individual psychosocial and adherence support needs in patients with psoriasis: a multinational two-stage qualitative and quantitative study. J Eur Acad Dermatol Venereol. 2014;28(6):763-770.

3. Augustin M, Holland B, Dartsch D, Langenbruch A, Radtke MA. Adherence in the treatment of psoriasis: a systematic review. Dermatology. 2011;222(4):363-374.

4. Carroll CL, Feldman SR, Camacho FT, Balkrishnan R. Better medication adherence results in greater improvement in severity of psoriasis. Br J Dermatol. 2004;151(4):895-897.

5. Feldman SR, Horn EJ, Balkrishnan R, et al. Psoriasis: improving adherence to topical therapy. J Am Acad Dermatol. 2008;59(6): 1009-1016.

6. Vangeli E, Bakhshi S, Baker A, et al. A systematic review of factors associated with non-adherence to treatment for immune-mediated inflammatory diseases. Adv Ther. 2015;32(11):983-1028.

7. Turner AP, Williams RM, Sloan AP, Haselkorn JK. Injection anxiety remains a long-term barrier to medication adherence in multiple sclerosis. Rehabil Psychol. 2009;54(1):116-121.

8. Bolge SC, Goren A, Tandon N. Reasons for discontinuation of subcutaneous biologic therapy in the treatment of rheumatoid arthritis: a patient perspective. Patient Prefer Adherence. 2015;9:121-131.

9. Kivitz A, Cohen S, Dowd JE, et al. Clinical assessment of pain, tolerability, and preference of an autoinjection pen versus a prefilled syringe for patient self-administration of the fully human, monoclonal antibody adalimumab: the TOUCH trial. Clin Ther. 2006;28(10): 1619-1629.

10. Paul C, Lacour JP, Tedremets L, et al. Efficacy, safety and usability of secukinumab administration by autoinjector/pen in psoriasis: a randomized, controlled trial (JUNCTURE). J Eur Acad Dermatol Venereol. 2015;29(6):1082-1090.

11. Bayas A. Improving adherence to injectable disease-modifying drugs in multiple sclerosis. Expert Opin Drug Deliv. 2013;10(3): 285-287.

12. Lugaresi A. Addressing the need for increased adherence to multiple sclerosis therapy: can delivery technology enhance patient motivation? Expert Opin Drug Deliv. 2009;6(9):995-1002.

13. Pozzilli C, Schweikert B, Ecari U, Oentrich W; BetaPlus Study group. Supportive strategies to improve adherence to IFN beta- $1 \mathrm{~b}$ in multiple sclerosis--results of the betaPlus observational cohort study. J Neurol Sci. 2011;307(1-2):120-126. 
14. Griffiths CE, Reich K, Lebwohl M, et al. Comparison of ixekizumab with etanercept or placebo in moderate-to-severe psoriasis (UNCOVER-2 and UNCOVER-3): results from two phase 3 randomised trials. Lancet. 2015;386(9993):541-551.

15. Gordon K, Blauvelt K, Langley R, et al. Ixekizumab for treatment of moderate-to-severe plaque psoriasis: 60-week results from a double-blind phase 3 induction and randomized withdrawal study (UNCOVER-1). American Academy of Dermatology - 73rd Annual Meeting; 2015.

16. Callis Duffin K, Bagel J, Bukhalo M, et al. Phase 3, open-label, randomized study of the pharmacokinetics, efficacy, and safety of ixekizumab following subcutaneous administration using a prefilled syringe or an autoinjector in patients with moderate-to-severe plaque psoriasis (UNCOVER-A). J Eur Acad Dermatol Venereol. Epub 2016 Aug 8.

17. Humira Patient Instructions for Use. Available from: http://www.rxabbvie.com/pdf/humirapen_PIL.pdf. Accessed January 26, 2016.

18. Enbrel Patient Instructions for Use. Available from: http://pi.amgen. com/united_states/enbrel/derm/enbrel_piu.pdf. Accessed January 26, 2016.
19. Pachon JA, Kivitz AJ, Heuer KU, Pichlmeier U. Assessing usability, label comprehension, pen robustness and pharmacokinetics of a selfadministered prefilled autoinjector pen of methotrexate in patients with rheumatoid arthritis. SAGE Open Med. 2014;2:2050312114564241.

20. Schiff M, Koo J, Jin E, et al. Usability and acceptability of the abatacept pre-filled autoinjector for the subcutaneous treatment of rheumatoid arthritis. Adv Ther. 2016;33(2):199-213.

21. Schwarzenbach F, Dao Trong M, Grange L, Laurent PE, Abry H, Cotten J, Granger C. Results of a human factors experiment of the usability and patient acceptance of a new autoinjector in patients with rheumatoid arthritis. Patient Prefer Adherence. 2014;8:199-209.

22. Ziemssen T, Sylvester L, Rametta M, Ross AP. Patient satisfaction with the new interferon Beta-1b autoinjector (BETACONNECT ${ }^{\mathrm{TM}}$ ). Neurol Ther. 2015;4(2):125-136.

23. Partsch CJ, Schnabel D, Ehtisham S, Johnstone HC, Zabransky M, Kiess W. Acceptability of the reusable SurePal ${ }^{\mathrm{TM}}$ self-injection device for Omnitrope(®) among pediatric patients: results from a questionnairebased, cross-sectional, multicenter observational study. Med Devices (Auckl). 2015;8:389-393. 


\section{Supplementary materials}

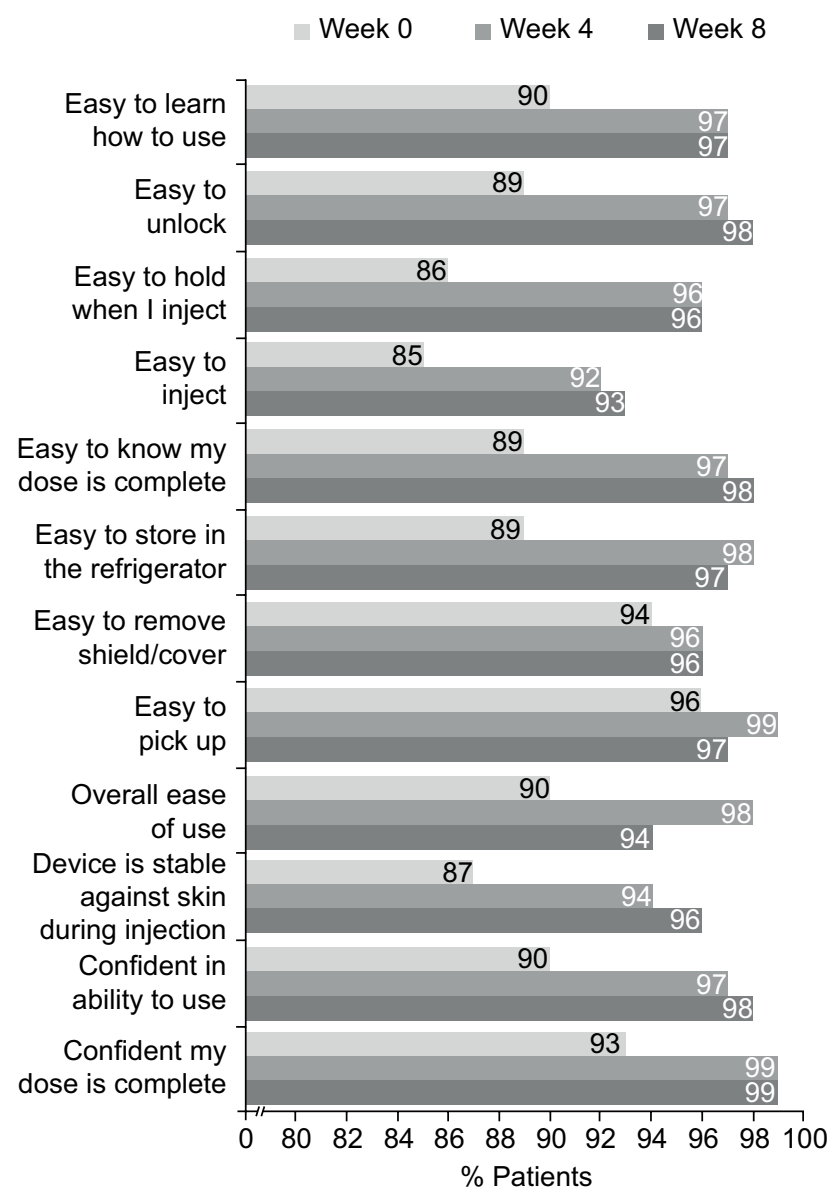

Figure SI Patient responses to the SQAAQ weeks $0-4$ and 8 (observed case data) - prefilled syringe group.

Notes: The proportion of patients that agreed or strongly agreed to each item of the SQAAQ is shown. Missing data were not imputed.

Abbreviation: SQAAQ, subcutaneous administration assessment questionnaire.

Video SI Ixekizumab autoinjector.

Medical Devices: Evidence and Research

\section{Publish your work in this journal}

Medical Devices: Evidence and Research is an international, peerreviewed, open access journal that focuses on the evidence, technology, research, and expert opinion supporting the use and application of medical devices in the diagnosis, monitoring, treatment and management of clinical conditions and physiological processes. The identification of novel

\section{Dovepress}

devices and optimal use of existing devices which will lead to improved clinical outcomes and more effective patient management and safety is a key feature. The manuscript management system is completely online and includes a quick and fair peer-review system. Visit http://www. dovepress.com/testimonials.php to read real quotes from authors. 